\title{
Synthesis of $\mathrm{Nano}_{\mathrm{TiO}_{2}}-\mathrm{Fe}_{2} \mathrm{O}_{3}$ Photocatalyst and photocatalytic
}

\section{degradation properties on oxytetracycline hydrochloride}

\author{
Ying Yang ${ }^{1}$, Qian Zhang ${ }^{2}$, Yuhang Deng ${ }^{3}$, Chuanda Zhu ${ }^{4}$, Di Wang ${ }^{2}$, \\ Zhenquan $\mathrm{Li}^{5,}$ \\ ${ }^{1}$ The Second Clinical College, Jining Medical University, Jining, China \\ ${ }^{2}$ The First Clinical College, Jining Medical University, Jining, China \\ ${ }^{3}$ School of Public Health, Jining Medical University, Jining, China \\ ${ }^{4}$ Institute of Forensic Medicine and Laboratory Medicine, Jining Medical University, Jining, China \\ ${ }^{5}$ School of Basic Medicine, Jining Medical University, Jining, China \\ * lizhq18@sina.com (Corresponding author)
}

\begin{abstract}
Keyword: Solvothermal; nanoTiO $\mathrm{T}_{2}-\mathrm{Fe}_{2} \mathrm{O}_{3}$ Photocatalyst; Photocatalytic Degradation
\end{abstract}
Abstract: Nano $\mathrm{TiO}_{2}-\mathrm{Fe}_{2} \mathrm{O}_{3}$ composite photocatalyst was synthesized by solvothermal method. $\mathrm{Fe}\left(\mathrm{NO}_{3}\right)_{3} \cdot 9 \mathrm{H}_{2} \mathrm{O}$ and titanium isopropoxide was used as precursor. The mixture of anhydrous ethanol, 2-propanol and diethylene glycol was used as solvent. The composite photocatalyst was characterized by X-ray diffractometry, transmission electron microscopy and UV-Vis diffuse reflectance spectroscopy. The composite was composed of anatase $\mathrm{TiO} 2$ and $\alpha-\mathrm{Fe}_{2} \mathrm{O}_{3}$. The average grain size of $\mathrm{TiO}_{2}$ and $\mathrm{Fe}_{2} \mathrm{O}_{3}$ are $18 \mathrm{~nm}$ and $16 \mathrm{~nm}$, respectively. The absorption spectrum of anatase $\mathrm{TiO}_{2}$ was in ultraviolet region, while $\alpha-\mathrm{Fe}_{2} \mathrm{O}_{3}$ exhibited high absorption in the visible light region of 400-600 nm. $\mathrm{TiO}_{2}-\mathrm{Fe}_{2} \mathrm{O}_{3}$ nano particles had light absorption in the region of 200 550 nm. When the initial concentration was $60 \mathrm{mg} / \mathrm{L}$ and $\mathrm{pH}$ was 5.5 , the degradation rate reached the maximum. Moreover, the $\mathrm{TiO}_{2}-\mathrm{Fe}_{2} \mathrm{O}_{3}$ nanocomposite was effective after three recycling times.

\section{Introduction}

In recent decades, the use of antibiotics brought more and more environmental problems, and the problems were attracted more and more attention. Oxytetracycline (OTC) is also called erythromycin. It is a kind of tetracyclin and is usually used. It is mainly used in the antibacterial agent for human diseases or in feed additive for animal husbandry, aquaculture and other fields ${ }^{[1]}$. However, majority of OTC was excreted in their original form after vivo metabolism by animal. Large amount of OTC entered into water. The accumulation of OTC increased the drug resistance of bacteria, which ultimately threaten the human health ${ }^{[2]}$. The usual wastewater treated technology is difficult to degrade OTC due to the good hydrophilicity and stable structure of OTC ${ }^{[3]}$. Therefore, it is urgent to find an effective water treatment technology to degrade OTC. The method of tetracycline activated sludge, biological filter or chlorination process could not effectively remove the tetracycline antibiotics in water ${ }^{[4]}$. Photocatalytic degredation is a new and promising environmental technology. $\mathrm{TiO}_{2}$ photocatalyst has been widely used because of its stable, non-toxic, high catalytic activity and non-secondary pollution ${ }^{[5]}$. But this technology has many defects ${ }^{[6,7]}$, such as the combination of electron and hole, the low photochemical catalysis efficiency, the wide band gap (about $3.2 \mathrm{eV}$ ), photochemical activity only in ultraviolet region and low utilization of 
sunlight $(<10 \%)$. The energy gap of $\alpha-\mathrm{Fe}_{2} \mathrm{O}_{3}$ is $2.3 \mathrm{eV}$. It could absorb the visible light and expand the photocatalyst the absorption scope, which would use the sunlight to carry on the photochemical catalysis. In this article, nano $\mathrm{TiO}_{2}-\mathrm{Fe}_{2} \mathrm{O}_{3}$ composite photocatalyst was synthesized by solvothermal method. The composite photocatalyst was used to degrade OTC in water. The effects of the initial concentration of OTC solution, $\mathrm{pH}$ and time on the degradation efficiency of OTC were also investigated.

\section{Experiment}

A certain amount of $\mathrm{Fe}\left(\mathrm{NO}_{3}\right)_{3} \cdot 9 \mathrm{H}_{2} \mathrm{O}$ and titanium isopropoxide (TTIP) were dispersed into the mixed alcohol solvent which containing $5 \mathrm{~mL}$ diethylene glycol, $8 \mathrm{~mL}$ anhydrous ethanol and $2 \mathrm{~mL}$ 2-Propanol. Then the mixed solution was transferred to a Teflon-lined stainless steel autoclave with a capacity of $50 \mathrm{~mL}$. The autoclave was sealed and kept at $180{ }^{\circ} \mathrm{C}$ for $4 \mathrm{~h}$. After cooling down to room temperature, the products were collected and washed in turn with deionized water, anhydrous ethanol respectively and then dried in the vacuum at $80{ }^{\circ} \mathrm{C}$.

The morphology and size of the samples were characterized through the transmission electron microscopy (TEM, JEOL-200cx). Crystallinity and phase analysis was performed by powder X-ray diffractometry (XRD) experiments on a Rigaku D/max 2500 with $\mathrm{Cu} K \alpha$ radiation $(\lambda=0.154059 \mathrm{~nm})$ scanning from 10 to 80 at a speed of $8 \% \mathrm{~min}$. The UV-vis absorption spectra of photocatalysts were recorded by a UV-vis spectrophotometer (Techcomp ltd. U3010).

For photocatalytic degradation, $70 \mathrm{~mL}$ aqueous OTC and $0.07 \mathrm{~g} \mathrm{TiO}_{2}-\mathrm{Fe}_{2} \mathrm{O}_{3}$ powder were added to a quartz tube and stirred for $1 \mathrm{~h}$ in the dark to equilibrate adsorption processes. A $300 \mathrm{~W}$ iodine tungsten lamp was used as visible light source. A 300W high-pressure mercury lamp was used as a UV light source, with main wavelength of $250-400 \mathrm{~nm}$. Under light conditions, $5 \mathrm{ml}$ of OTC solution was taken every $1 \mathrm{~h}$, and the supernatant was centrifuged. The residual concentration of the OTC solution was determined by U3010 UV spectrophotometer at a wavelength of $355 \mathrm{~nm}$.

\section{Results and Discussion}

The XRD patterns of $\mathrm{TiO}_{2}-\mathrm{Fe}_{2} \mathrm{O}_{3}$ is shown in Fig. 1. Anatase $\mathrm{TiO} 2$ and $\alpha-\mathrm{Fe}_{2} \mathrm{O}_{3}$ were observed in the profile. According to Scherrer equation, it can be calculated the average grain size of $\mathrm{TiO}_{2}$ and $\mathrm{Fe}_{2} \mathrm{O}_{3}$ are $18 \mathrm{~nm}$ and $16 \mathrm{~nm}$, respectively.

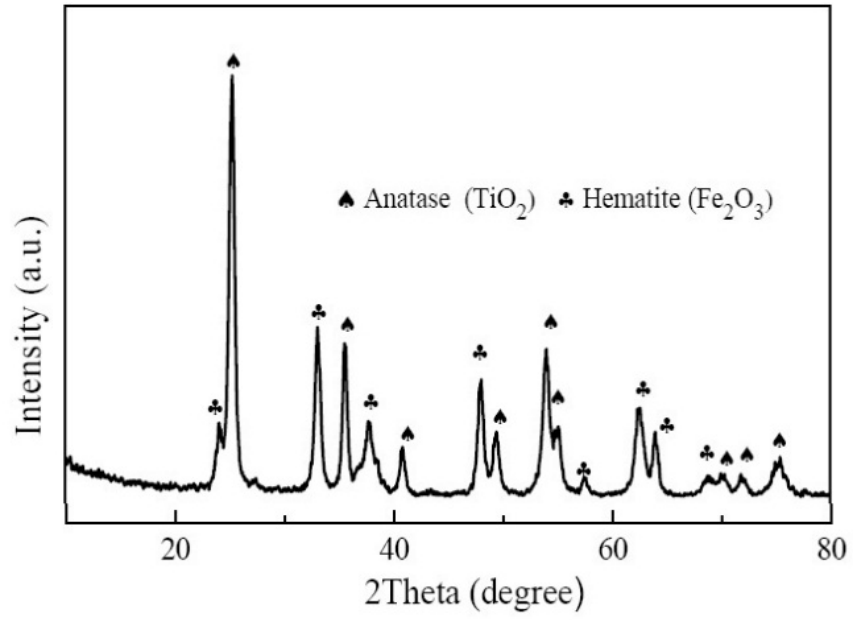

Fig.1 XRD pattern of $\mathrm{TiO}_{2}-\mathrm{Fe}_{2} \mathrm{O}_{3}$ composites

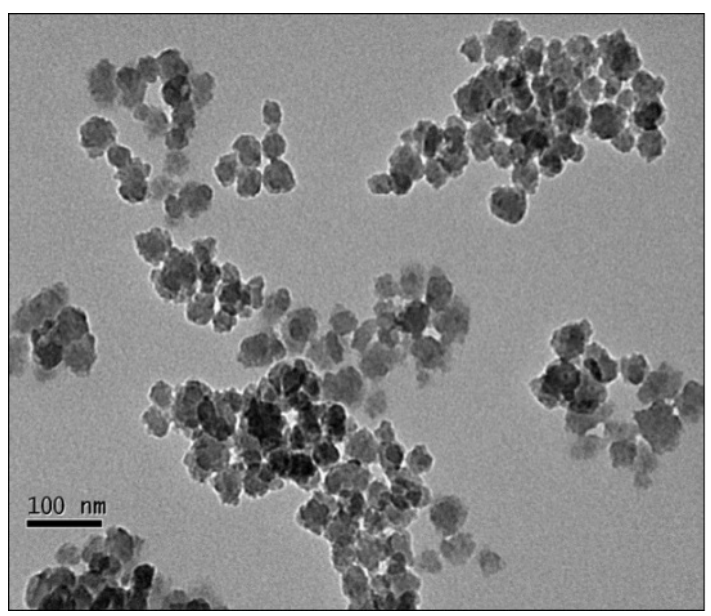

Fig.2 TEM micrograph of $\mathrm{TiO}_{2}-\mathrm{Fe}_{2} \mathrm{O}_{3}$

TEM images of $\mathrm{TiO}_{2}-\mathrm{Fe}_{2} \mathrm{O}_{3}$ composites is shown in Fig.2. The particles were spherical and were about $15-20 \mathrm{~nm}$. This is in accordance with the XRD results. 
Figure 3 shows the UV-vis absorption spectrum of anatase $\mathrm{TiO}_{2}, \alpha-\mathrm{Fe}_{2} \mathrm{O}_{3}$ and $\mathrm{TiO}_{2}-\mathrm{Fe}_{2} \mathrm{O}_{3}$ composites, respectively. The absorption spectrum of anatase $\mathrm{TiO}_{2}$ was in ultraviolet region, while $\alpha-\mathrm{Fe}_{2} \mathrm{O}_{3}$ exhibited high absorption in the visible light region of $400-600 \mathrm{~nm}$. $\mathrm{TiO}_{2}-\mathrm{Fe}_{2} \mathrm{O}_{3}$ nano particles had light absorption in the region of 200 550 nm. The absorption spectrum of $\mathrm{TiO}_{2}-\mathrm{Fe}_{2} \mathrm{O}_{3}$ showed an obvious red shift compared with that of anatase $\mathrm{TiO}_{2}$.

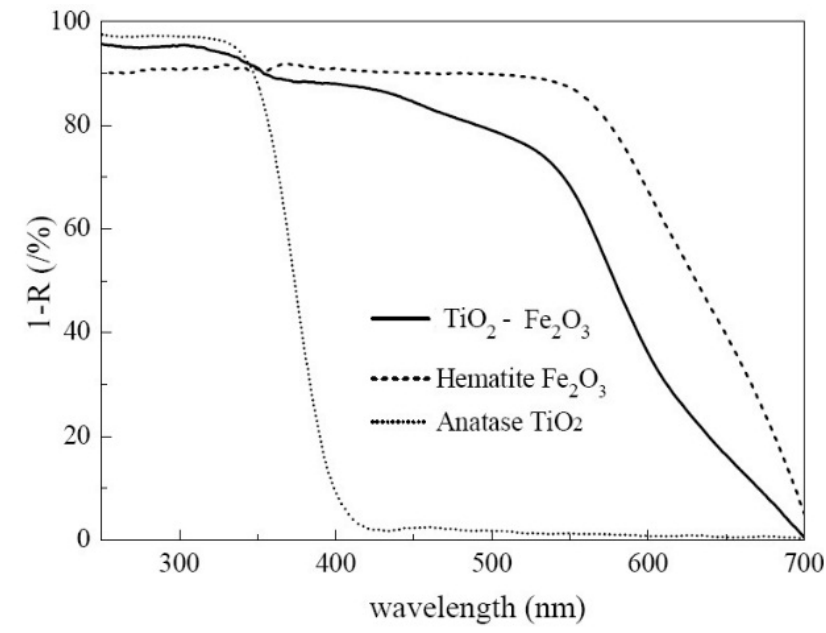

Fig.3 UV-vis absorption spectra of $\mathrm{TiO}_{2}-\mathrm{Fe}_{2} \mathrm{O}_{3}$ composites, anatase $\mathrm{TiO}_{2}$ and $\alpha-\mathrm{Fe}_{2} \mathrm{O}_{3}$

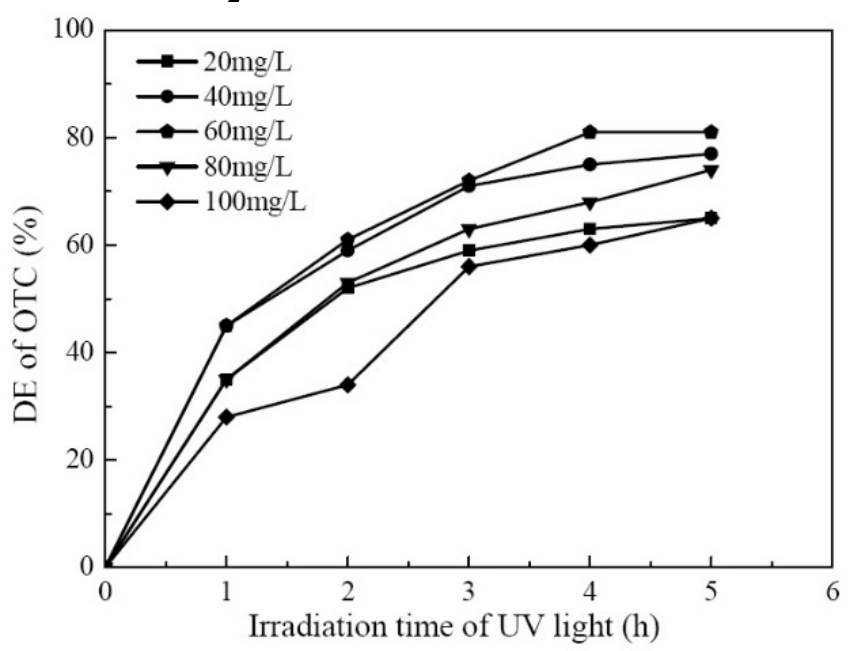

Fig.4 Degradation rate(\%) of OTC on different initial concentration under UV light

The influence of OTC initial concentration on the degradation rate under the UV light irradation (added $0.07 \mathrm{~g} \mathrm{TiO}_{2}-\mathrm{Fe}_{2} \mathrm{O}_{3}$ ) is shown in Fig.4. When the initial concentration was lower than $60 \mathrm{mg} / \mathrm{L}$, the degradation rate increased with increase of OTC initial concentration. However, when the initial concentration is higher than $60 \mathrm{mg} / \mathrm{L}$, the OTC degradation rate decreased with increase of OTC initial concentration. Photocatalytic reactions are mainly photo-generated electrons and holes directly or indirectly redox reaction with the adsorption of OTC molecules on the surface of the catalyst. The indirect reaction is the photo-generated electrons and holes react with the water molecules or hydroxide ions on the surface of the catalyst to produce strongly oxidizing substances, such as $\bullet \mathrm{OH}$ and $\bullet \mathrm{O}^{2-}$. Then these strongly oxidizing substances react with the OTC molecules. It is generally believed that indirect oxidation plays a major role in the degradation of OTC. When the initial concentration of OTC is low, the OTC molecules adsorbed on the surface of catalyst are less, which makes the degradation rate lower. When the initial concentration of OTC is more than 60mg / $\mathrm{L}$, the surface adsorption of the catalyst is supersaturated. OTC and intermediates will accumulate on the surface of the catalyst. The adsorption capacity of the catalyst surface on water and hydroxide ions is reduced, so that the number of $\bullet \mathrm{OH}$ and $\bullet \mathrm{O} 2$ - groups with strong oxidization is reduced, so that the degradation rate tends to decrease with the increase of OTC initial concentration. So $60 \mathrm{mg} / \mathrm{L}$ is the best initial concentration and the degradation rate can reached to $85 \%$.

The influence of initial $\mathrm{pH}$ of OTC on the degradation rate under the UV/vis light irradation (initial concentration of OTC is $60 \mathrm{mg} / \mathrm{L}$ ) is shown in Fig.5. When the $\mathrm{pH}$ was lower than 5.5, the degradation rate increased with $\mathrm{pH}$ increasing. However, when the $\mathrm{pH}$ is larger than 5.5, the degradation rate decreased with $\mathrm{pH}$ increasing. This trend was in good agreement with photocatalytic degradation behavior, indicating that the photocatalytic process was limited by the adsorption of OTC at the surface of catalyst. When $\mathrm{pH}$ was equal to 5.5, the degradation rate reached the maximum at $5 \mathrm{~h}$. The degradation rates under UV and vis light irradation was $50 \%$ and $85 \%$, respectively. 


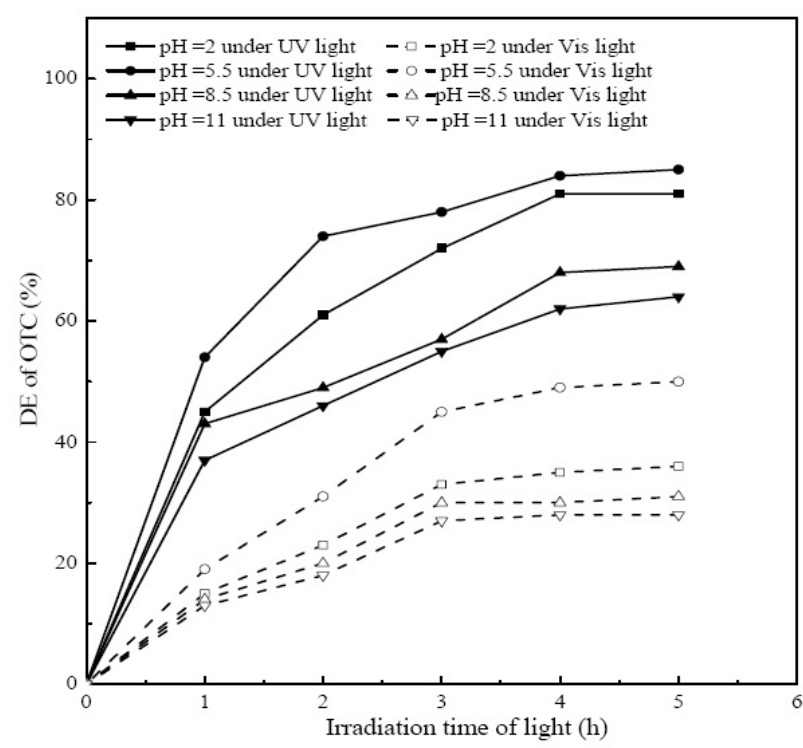

Fig.5 Effect of $\mathrm{pH}$ on degradation rate of OTC $(60 \mathrm{mg} / \mathrm{L})$ under $\mathrm{UV}$ and visible light

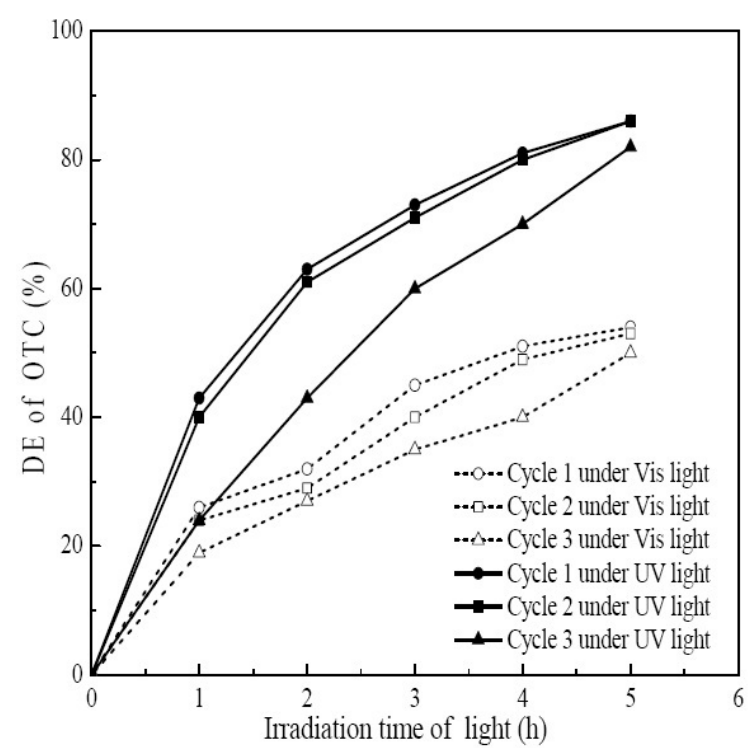

Fig.6 Photocatalytic activities for the degradation of OTC under UV-vis light for 3 cycles

The influence of $\mathrm{TiO}_{2}-\mathrm{Fe}_{2} \mathrm{O}_{3}$ nanocomposite recycling on the degradation rate is shown in Fig.6. After one, two and three recycles, the degradation rates under UV irradation were $86 \%, 86 \%$ and $82 \%$, respectively. And the degradation rates under vis irradation were 54\%, 53\% and 50\%, respectively. The degradation rate declined slightly with the increasing number of cycles. So $\mathrm{TiO}_{2}-\mathrm{Fe}_{2} \mathrm{O}_{3}$ nanocomposite was effective after three recycling times.

\section{Conclusions}

Nano $\mathrm{TiO}_{2}-\mathrm{Fe}_{2} \mathrm{O}_{3}$ composite photocatalyst was synthesized by solvothermal method. It was characterized by XRD, TEM and UV-vis spectrum. The results showed the composite consisted of anatase $\mathrm{TiO} 2$ and $\alpha-\mathrm{Fe}_{2} \mathrm{O}_{3}$ with particle size of $20 \mathrm{~nm}$. It exhibited strong absorption from 200 to 550 $\mathrm{nm}$. The degradation rate reached maximum at proper conditions (OTC concentration was $60 \mathrm{mg} / \mathrm{L}$ and $\mathrm{pH}$ was 5.5). The degradation rates under vis irradation and UV irradation were 50\% and $85 \%$ at $5 \mathrm{~h}$, respectively.

\section{Acknowledgement}

This work was supported by the National Undergraduate Innovation Training Program of Ministry of Education (No. 201610443019) and Undergraduate Innovation Training Program of Jining Medical University (No. cx2016019).

\section{References}

[1] Liping Huang, Donghui Chen: Technology of Water Treatment Vol.37 (2011), p. 77

[2] Pereira JHOS, Vilar VJP, Borges MT: Solar Energy Vol.85 (2011), p. 2732

[3] Liping Huang, Donghui Chen: Chinese Journal of Environmental Engineering Vol.6 (2012), p. 57

[4] Chun Zhao, Pelaez, Miguel, Xiaodi Duan: Applied Catalysis B Vol.134 (2013), p. 83

[5] Huan Zhao, Jiao Li, Weisheng Guan: Applied Chemical Industry Vol.41 (2012), p.1353.

[6] Bennemla M, Chabani M, Amrane A: International Journal of Chemical Kinetics Vol.48 (2016), p. 464

[7] Jo WK, Kumar S, Isaacs MA: Applied Catalysis B Vol.201 (2017), p. 159 